\title{
Influence of Bed Temperature on Heat Shrinkage Shape Error in FDM Additive Manufacturing of the ABS-Engineering Plastic
}

\author{
Young-Hyu Choi', Cheol-Min Kim², Hwan-Seock Jeong'2, Jeong-Ho Youn ${ }^{3}$ \\ ${ }^{1}$ Department of Mechanical Engineering, Changwon National University, Changwon, Republic of Korea \\ ${ }^{2}$ Department of Mechanical Design, Changwon National University, Changwon, Republic of Korea \\ ${ }^{3}$ Turf Grass Science Institute, Hanul Inc., Hapcheon-Gun, Republic of Korea \\ Email: yhchoi@changwon.ac.kr,kcm0619@changwon.ac.kr
}

How to cite this paper: Choi, Y.-H., Kim, C.-M., Jeong, H.-S. and Youn, J.-H. (2016) Influence of Bed Temperature on Heat Shrinkage Shape Error in FDM Additive Manufacturing of the ABS-Engineering Plastic. World Journal of Engineering and Techno$\log y, 4,186-192$.

http://dx.doi.org/10.4236/wjet.2016.43D022

Received: September 21, 2016

Accepted: October 13, 2016

Published: October 20, 2016

\begin{abstract}
In case of manufacturing hexahedral ABS (Acrylonitrile Butadiene Styrene) plastic components using a FDM (Fused Deposition Modeling)-based 3D printer, undesirable shape errors occur in the product due to heat shrinkage. This paper experimentally observed the influence of the bed temperature change on the deformed shape errors of a hexahedral specimen of $100 \times 50 \times 50 \mathrm{~mm}^{3}$ produced by using a $3 \mathrm{D}$ printer. During printing work, the head nozzle temperature was kept at $240^{\circ} \mathrm{C}$ and the head speed was set at $50 \mathrm{~mm} / \mathrm{s}$. The chamber was enclosed with a PC-plate. 3D printing was conducted at four different bed temperatures; $50^{\circ} \mathrm{C}, 70^{\circ} \mathrm{C}, 90^{\circ} \mathrm{C}$, and $110^{\circ} \mathrm{C}$. After the produced specimens naturally cooled down to room temperature, their deformed shape errors were measured. As a result, the higher the bed temperature, the lower the deformed shape errors of the specimens were. However, if the bed temperature had exceeded $120^{\circ} \mathrm{C}$, laminating adhesion became poor. That seems to occur because of the material phase change and can make 3D printing work very hard as a consequence. Results of this study can be helpful to set optimum bed temperature condition in FDM additive manufacturing.
\end{abstract}

\section{Keywords}

FDM, Additive Manufacturing, 3D Printing, Heat Shrinkage, Shape Error, ABS

\section{Introduction}

When FDM (Fused Deposition Modeling) [1] 3D printers are used to make plastic resin parts, the product quality and accuracy are influenced by a range of manufacturing conditions and parameters, e.g. internal and external environmental temperatures, the 
head speed and the printer vibrations. Some materials relatively easily meet the conditions for manufacturing, while others require a challenging adjustment of parameters. ABS (Acrylonitrile Butadiene Styrene) and PLA (Poly Lactic Acid) resin materials for industrial plastics are largely used in manufacturing parts with FDM 3D printers [2] [3]. As the material for industrial plastics most widely used for mockups, ABS is easily sanded and painted but substantially shrinks by heat [4] [5]. In particular, to reduce the shape errors resulting from the heat shrinkage in manufacturing ABS parts with the FDM-based 3D printing, the temperature settings for the bed and the inside and outside of the chamber are highly important. This paper experimentally observed the effects of the bed temperature in a $3 \mathrm{D}$ printer on the shape errors of ABS parts caused by the heat shrinkage in the FDM-AM (Fused Deposition Modeling-Additive Manufacturing).

\section{3D Printing ABS and the Heat Shrink Shape Errors}

\subsection{Design of Specimen and Definition of Shape Errors}

Figure 1(a) shows the ABS specimen shape and its dimension $\left(100 \times 50 \times 50 \mathrm{~mm}^{3}\right)$. Figure 1(b) shows the parameters for defining the shape errors resulting from the heat shrinkage.

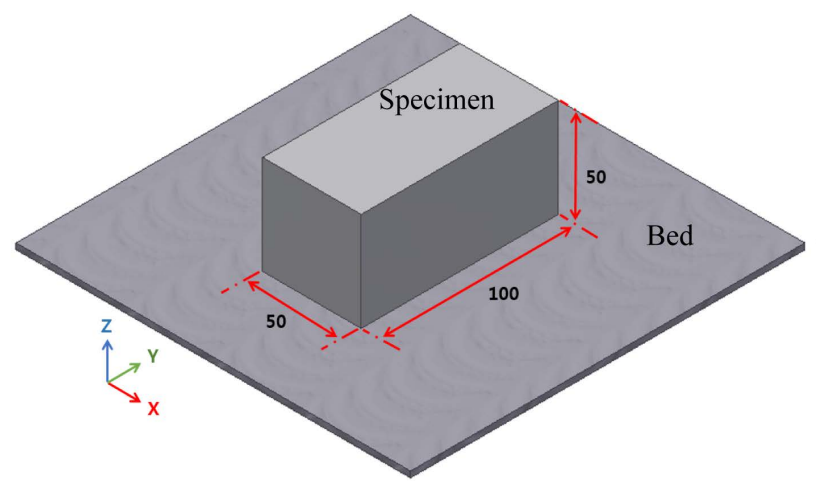

(a)

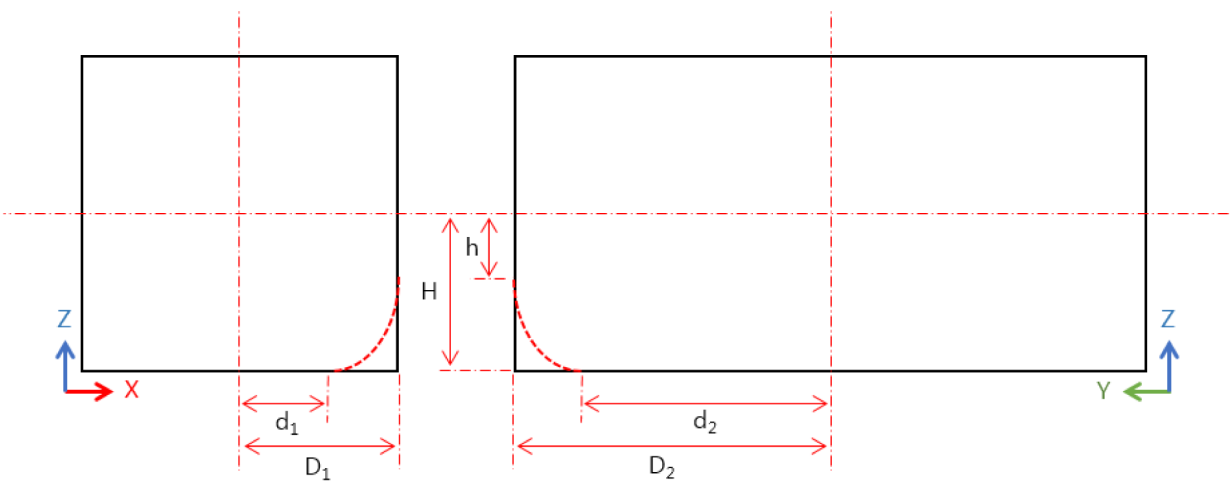

(b)

Figure 1. Specimen part model and parameters to describe shape errors. (a) Specimen part on the bed; (b) Parameters to describe shape deformation errors. 
The percentage shape errors caused by the heat shrinkage are $\mathrm{X}, \mathrm{Y}$ and $\mathrm{Z}$ percentage errors, each of which is defined as follows.

$$
\begin{aligned}
& \text { X percentage error: } \Delta D_{1}=\frac{D_{1}-d_{1}}{D_{1}} \times 100 \\
& \text { Y percentage error: } \Delta D_{2}=\frac{D_{2}-d_{2}}{D_{2}} \times 100 \\
& \text { Z percentage error: } \Delta H=\frac{H-h}{H} \times 100
\end{aligned}
$$

Table 1 outlines the material properties of the ABS specimens used in the present experiment.

\subsection{Additive Manufacturing ABS Specimens}

1) $3 D$ printer for specimen fabrication

To fabricate the ABS specimens with 3D printing, an FDM 3D printer was built as in Figure 2 based on the FDM 3D printer described by Kun [6]. The FDM 3D printer built here consisted of the following components: a Mendel head extruding the materials, a 3-axis positioning stage for the head, a heating bed supporting the layered material and controlling the temperature, a closed chamber maintaining the temperature of work space. The chamber measured $600 \times 600 \times 500 \mathrm{~mm}^{3}$. The exterior size of the FDM 3D printer was $450 \times 450 \times 400 \mathrm{~mm}^{3}$. The bed measured $200 \times 200 \mathrm{~mm}^{2}$. The range of additive manufacturing was $200 \times 200 \times 140 \mathrm{~mm}^{3}$. As the $3 \mathrm{D}$ printing slicer,

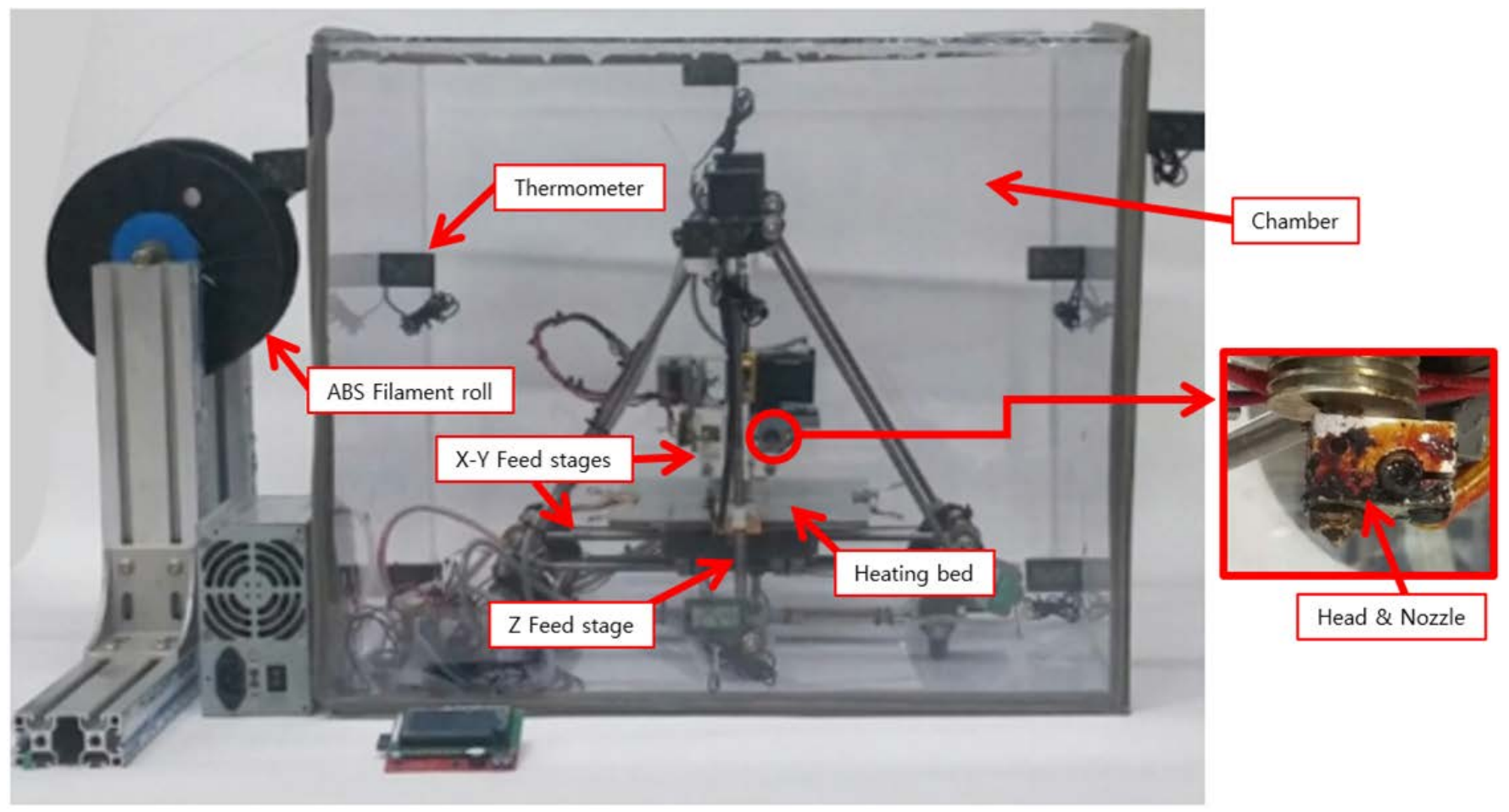

Figure 2. FDM 3D printer system. 
Table 1. ABS material specifiaction.

\begin{tabular}{cc}
\hline Meterial Specification & Value \\
\hline Specific Gravity $\left(\mathrm{GMS} / \mathrm{cm}^{3}\right)$ & 1.05 \\
Tensile Strength $(\mathrm{Mpa})$ & 34 \\
Elongation $(\%)$ & 50.00 \\
Softening Point $\left({ }^{\circ} \mathrm{C}\right)$ & 104 \\
\hline
\end{tabular}

Cura, an open source tool offered by Ultimaker, was used [7]. The bed was designed to feature the temperature control so as to maintain the temperature settings for heating.

2) $3 \mathrm{D}$ printing experiment

First, for the AM, Inventor program for 3D CAD modelling [8] was used to create a hexahedral 3D-solid specimen measuring $100 \times 50 \times 50 \mathrm{~mm}^{3}$ and converted it to an STL (Stereo Lithography) file. Next, the Cura slicer program was used to convert the STL file to a G-code format compatible with the FDM device. Then, the file was stored on an SD (Secure Digital) card, which was in turn inserted into the 3D printer's mainboard to initiate the specimen manufacturing.

For the $3 \mathrm{D}$ printing, the $\mathrm{ABS}$ filament material was fed into the head at a rate pre-set by the slicer. The incoming filament was fused and heated at a pre-set temperature in the head before being extruded by the nozzle. The fused filament from the nozzle tip was layered on the bed. While being layered, the extruded filament material was transferred by the 3-axis stage through the pre-set channel to mold the layer surface. This AM process was repeated to fabricate the final specimens.

During the FDM-based 3D printing, the nozzle diameter, temperature, speed and layer height were set at $0.8 \mathrm{~mm}, 240^{\circ} \mathrm{C}, 50 \mathrm{~mm} / \mathrm{s}$ and $0.3 \mathrm{~mm}$, respectively. Also, the infill percentage was set at $100 \%$, where the material shrunk most. The platform adhesion type was not used. The mean outside air temperature was maintained at $27^{\circ} \mathrm{C}$ during the experiment. It took 6 hours and 16 minutes to fabricate the specimens, including the printing but excluding the time spent on the 3D printer setup. Upon completion of the $3 \mathrm{D}$ printing, the specimens were naturally cooled down for 2 hours at room temperature. Then, the shape errors caused by heat shrinkage were measured.

For considering the phenomenon that the ABS filament layers fail to settle on the bed due to the temperature difference between bed and ABS filament [9], the following five cases of different bed temperatures were applied to the $3 \mathrm{D}$ printing experiment, where three specimens were manufactured per temperature setting.

Case 1: Bed temperature $40^{\circ} \mathrm{C}$, Case 2: Bed temperature $50^{\circ} \mathrm{C}$, Case 3: Bed temperature $70^{\circ} \mathrm{C}$, Case 4 : Bed temperature $90^{\circ} \mathrm{C}$, Case 5 : Bed temperature $110^{\circ} \mathrm{C}$.

\subsection{Results and Consideration}

Table 2 and Figure 3 show the shape errors caused by the heat shrinkage of the specimens measured in each of the five AM experimental cases. Table 2 outlines the mean percentage of shape errors attributable to the heat shrinkage of three specimens fabri- 

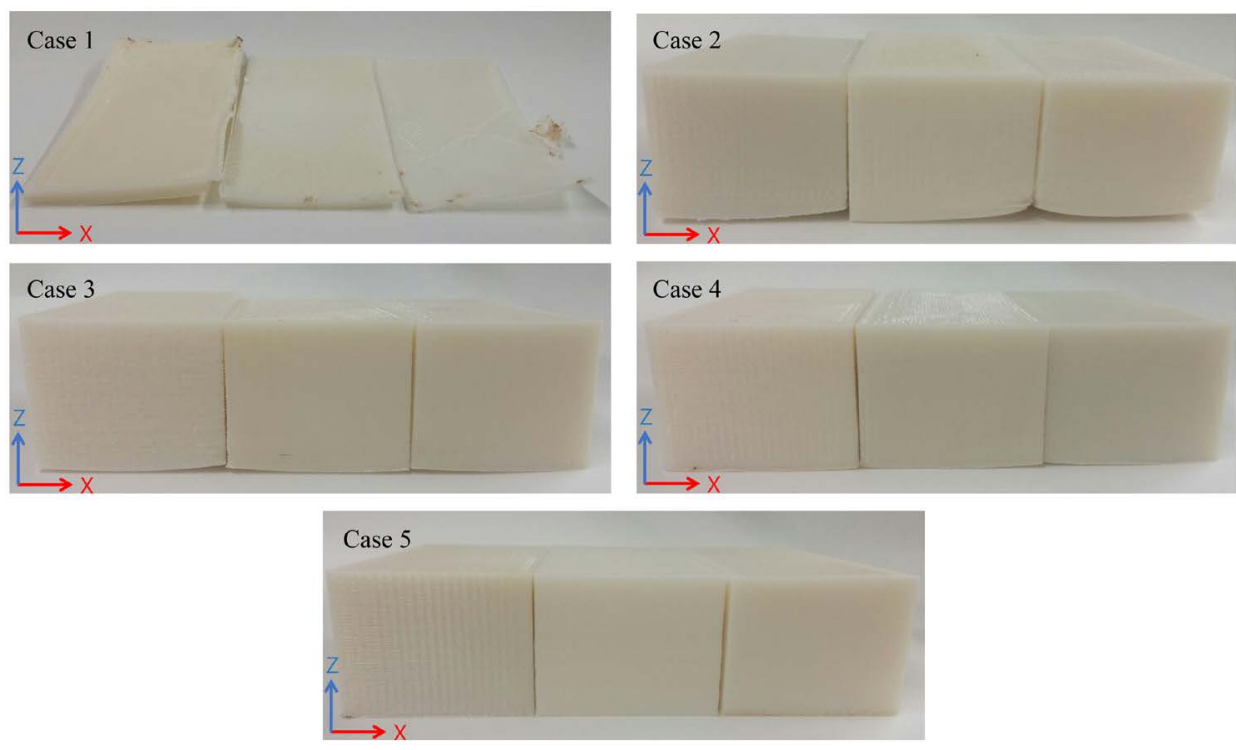

(a)
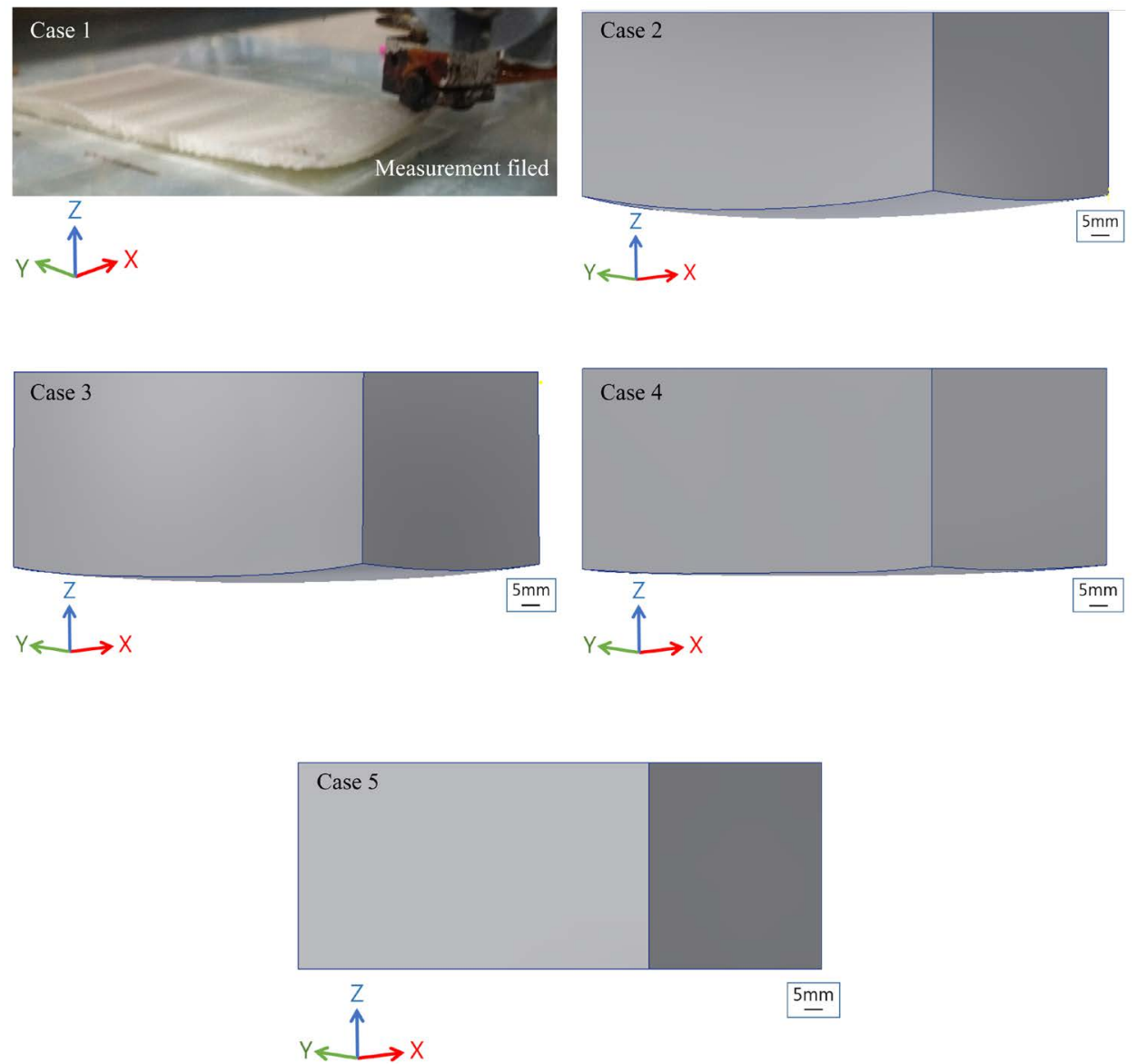

(b)

Figure 3. Measured heat shrink shape erroes of the ABS specimens in AM. (a) ABS specimens made by AM experiment; (b) 3D scanned heat shrink form errors. 
Table 2. Measured average heat shrinkage shape errors of the ABS specimens made by AM experiment.

\begin{tabular}{|c|c|c|c|c|c|c|c|}
\hline \multirow{2}{*}{$\begin{array}{c}\text { Case of } \\
\text { experiment }\end{array}$} & \multirow{2}{*}{$\begin{array}{l}\text { Bed temp. } \\
\quad\left({ }^{\circ} \mathrm{C}\right)\end{array}$} & \multicolumn{3}{|c|}{ Chamber temperature at $\left({ }^{\circ} \mathrm{C}\right)$} & \multicolumn{3}{|c|}{ Heat shrinkage shape errors (\%) } \\
\hline & & Top & Mid & Bottom & $\begin{array}{c}\text { X-percentage } \\
\text { error }\end{array}$ & $\begin{array}{c}\text { Y-percentage } \\
\text { error }\end{array}$ & $\begin{array}{c}\text { Z-percentage } \\
\text { error }\end{array}$ \\
\hline 1 & 40 & 32.5 & 31.3 & 28.7 & Fail in AM & Fail in AM & Fail in AM \\
\hline 2 & 50 & 33.2 & 30.9 & 29.3 & 93.7 & 94.2 & 14.0 \\
\hline 3 & 70 & 37.2 & 32.5 & 30.6 & 80.9 & 84.6 & 7.9 \\
\hline 4 & 90 & 38.0 & 33.6 & 31.6 & 74.1 & 72.1 & 6.0 \\
\hline 5 & 110 & 45.8 & 34.1 & 31.2 & 3.44 & 4.0 & 0.24 \\
\hline
\end{tabular}

cated at different temperatures inside the chamber. Figure 3(a) shows three specimens manufactured at each different temperature of the bed. Figure $3(b)$ shows the result of 3D scanning measurement. The shape errors of specimens were measured with COMET 6(8M), a 3D shape measuring device from German Steinbichler [10].

As shown in Table 2, the heat shrinkage of the ABS material substantially increased when the temperature of the bed was $40^{\circ} \mathrm{C}$ or lower, which hampered the inter-layer adhesion. As the layers were separated from one another, the specimen manufacturing failed. When the temperature of the bed was $90^{\circ} \mathrm{C}$ or lower, in comparison to $110^{\circ} \mathrm{C}$, the shape errors due to the heat shrinkage remarkably increased. Given the ABS' softening point being $104^{\circ} \mathrm{C}$, the bed temperature of $110^{\circ} \mathrm{C}$ paralleled the $\mathrm{ABS}$ 's softening point, which left a small temperature gap between the $\mathrm{ABS}$ material and the bed during the AM, resulting in little heat shrinkage. By contrast, when the bed temperature was below $90^{\circ} \mathrm{C}$ and much lower than that of the softening point, the significant temperature gap between the ABS material and the bed during the AM seemed to increase the heat shrinkage to a great extent. These experimental findings suggest the shape errors may be decreased by setting the bed at a temperature similar to that of the heat shrinkage of the ABS and thus reducing the shrinkage of each edge of the specimen.

\section{Conclusions}

The present experimental observation of the effects of bed temperatures on the shape errors caused by the heat shrinkage of ABS specimens in the FDM-AM shed light on the following.

It was impossible to fabricate the specimens on account of the inter-layer separation resulting from the heat shrinkage in the $\mathrm{AM}$ of $\mathrm{ABS}$ in $3 \mathrm{D}$ printing when the bed temperature was $40^{\circ} \mathrm{C}$, which was lower than that of the softening temperature $\left(104^{\circ} \mathrm{C}\right)$ of the ABS by over $60^{\circ} \mathrm{C}$.

When the bed temperature increased within the range from $50^{\circ} \mathrm{C}$ to $90^{\circ} \mathrm{C}$, the shape errors caused by the heat shrinkage of the ABS specimens decreased in proportion to the difference between the bed temperature and the ABS' softening temperature. When the bed temperature was $110^{\circ} \mathrm{C}$, approaching the ABS' softening temperature $\left(104^{\circ} \mathrm{C}\right)$, 
the specimens manufactured hardly showed the shape errors ascribable to the heat shrinkage. When the bed temperature was set at $110^{\circ} \mathrm{C}$ close to the ABS' softening temperature $\left(104^{\circ} \mathrm{C}\right)$, the inter-layer adhesion improved following the extrusion of $\mathrm{ABS}$ because the ABS material was subjected to a slow phase transformation from the liquid phase to solid phase, and thus hardened slowly.

Therefore, to minimize the shape errors attributable to the heat shrinkage in ABS specimens fabricated with the AM (Additive Manufacturing), the temperature of the bed needs to remain close to the ABS' softening temperature throughout the AM process. Then, upon the AM being finished, the specimens should be cooled down. The present findings will benefit the temperature settings for manufacturing precision products with FDM 3D printing.

The present paper concerned an experimental manufacturing of hexahedral specimens. Further studies should explore the fabrication of diverse specimens of different shapes and build on the experimental findings to develop a theoretical model for prediction.

\section{Acknowledgements}

This work (Grants No. S2176447) was supported by the technological convergence R \& D program funded by Korea small and medium business administration in 2014-2016.

\section{References}

[1] Masood, S.H. (1996) Interlligent Rapid Prototyping with Fused Deposition Modelling. Rapid Prototyping Journal, 2, 24-33. http://dx.doi.org/10.1108/13552549610109054

[2] Dul, S., Fambri, L. and Pegoretti, A. (2016) Fused Deposition Modelling with ABS-Graphene Nanocomposites. Compositers: Part A, 85, 181-191. http://dx.doi.org/10.1016/j.compositesa.2016.03.013

[3] Weng, Z., Wang, J., Senthil, T. and Wu, L. (2016) Mechanical and Thermal Properties of ABS/Montmorillonite Nanocomposites for Fused Deposition Modeling 3D Printing. Materials and Design, 102, 276-283. http://dx.doi.org/10.1016/j.matdes.2016.04.045

[4] Schmutzler, C., Zimmermann, A. and Zaeh, M.F. (2016) Compensating Warpage of 3D Printed Parts Using Free-Form Deformation. Procedia CIRP, 41, 1017-1022. http://dx.doi.org/10.1016/j.procir.2015.12.078

[5] Minetola, P., Iuliano, L. and Marchiandi, G. (2016) Benchmarking of FDM Machines through Part Quality Using IT Grades. Procedia CIRP, 41, 1027-1032. http://dx.doi.org/10.1016/j.procir.2015.12.075

[6] Kun, K. (2016) Reconstruction and Development of a 3D Printer Using FDM Technology. Procedia Engineering, 149, 203-211. http://dx.doi.org/10.1016/j.proeng.2016.06.657

[7] http://software.ultimaker.com

[8] http://www.autodesk.com/products/inventor/overview

[9] Han, J.G. (2016) Effects of the Processing Conditions on the Mechanical Properties of the Sculpture by 3D Printing (FDM). M.S Dissertation, Soonchunhyang University, Korea.

[10] http://optotechnik.zeiss.com/en/products/3d-scanning/comet-6 
Submit or recommend next manuscript to SCIRP and we will provide best service for you:

Accepting pre-submission inquiries through Email, Facebook, LinkedIn, Twitter, etc. A wide selection of journals (inclusive of 9 subjects, more than 200 journals)

Providing 24-hour high-quality service

User-friendly online submission system

Fair and swift peer-review system

Efficient typesetting and proofreading procedure

Display of the result of downloads and visits, as well as the number of cited articles

Maximum dissemination of your research work

Submit your manuscript at: http://papersubmission.scirp.org/

Orcontactwjet@scirp.org 